\title{
Neonatal and maternal outcome in term primigravida with isolated oligohydramnios
}

\author{
Shelly Agarwal, Samta Gupta* \\ Department of Obstetrics and Gynecology, SMS and R Greater Noida, Uttar Pradesh, India
}

Received: 04 November 2018

Accepted: 06 December 2018

\section{*Correspondence:}

Dr. Samta Gupta,

E-mail: samtagup12@gmail.com

Copyright: $\odot$ the author(s), publisher and licensee Medip Academy. This is an open-access article distributed under the terms of the Creative Commons Attribution Non-Commercial License, which permits unrestricted non-commercial use, distribution, and reproduction in any medium, provided the original work is properly cited.

\begin{abstract}
Background: The aim of this study is to evaluate the maternal and perinatal outcome in term primigravida with isolated oligohydramnios.

Methods: A retrospective, case-control study was carried out in the department of OBG, School of Medical Sciences and Research, Sharda Hospital, Greater Noida from November 2014 to October 2017. The study population comprised of low-risk primigravida with singleton, term pregnancy, with vertex presentation and intact membranes. After meeting the inclusion and exclusion criterion, the study population was divided into cases $(\mathrm{n}=51)$ and control group (176) and the results were analyzed in reference to rate of induction of labour, C. Section rate and the perinatal outcome.

Results: Isolated oligohydramnios is associated with increased rate of induction of labour and increased operative interference, but perinatal outcome in terms of mean birth weight, Apgar score at $5 \mathrm{~min}$ and NICU admissions for over 24 hours, are not statistically significant in comparison with control group.

Conclusions: Isolated oligohydramnios is not an indicator of adverse perinatal outcome.
\end{abstract}

Keywords: Isolated oligohydramnios, Term primigravida

\section{INTRODUCTION}

Amniotic fluid not only surrounds the foetus from early pregnancy, but also plays an important role in growth and development of the foetus. The volume of amniotic fluid varies with gestational age. It increases gradually till 34 weeks of pregnancy and then remain more or less constant till 38 weeks (approximately 800-1000 ml). Thereafter it reduces by $100 \mathrm{ml}$ per week and is about $400 \mathrm{ml}$ at 40 weeks of gestation. But when Amniotic Fluid Volume (AFV) becomes abnormally decreased in the late second or third trimester of pregnancy, it is known as oligohydramnios. Oligohydramnios can be defined in many ways: Amniotic fluid volume less than $5 \%$ for a specific gestational age, $\mathrm{AFI}<5 \mathrm{~cm}$ or maximal deepest pocket $<2 \mathrm{~cm} .{ }^{1}$ Infact, the term oligohydramnios, defined as Amniotic Fluid Index $\leq 5$ was originally defined by Phelan et al, The ultrasonographic diagnosis of oligohydramnios is usually based on $\mathrm{AFV} \leq 5 \mathrm{~cm}$ or a single deepest pocket (SDP) of amniotic fluid $\leq 2 \mathrm{~cm} .{ }^{2,3}$ Of these, SDP is the best method for diagnosing it 4; most studies evaluate adverse outcomes using AFI. Reduced liquor or oligohydramnios is more likely associated with foetal growth restriction, a placental abnormality or a maternal complication such as preeclampsia, renal or a vascular disease. ${ }^{3}$ Therefore, the presence of oligohydramnios is usually a cause of concern to all obstetricians as it is co-related with adverse pregnancy outcomes such as higher rates of growth restriction and stillbirths, increased incidence of foetal distress, increased meconium aspiration as well as NICU (Neonatal Intensive Care Unit) stay. This commonly becomes an indication of labour induction and increased operative interference. 
So, the investigation of third trimester oligohydramnios includes mainly evaluation of rupture of membranes or any associated pathology, followed by ultrasonography to confirm the diagnosis. This is usually followed by Umbilical Artery Doppler evaluation to rule out uteroplacental insufficiency and growth restriction.

The present study was carried out to observe the effect of isolated oligohydramnios (IO) on perinatal outcome in term, low risk primigravidas.

\section{METHODS}

A retrospective, case-control study was carried out in the department of OBG, School of Medical Sciences and Research, Sharda Hospital, Greater Noida from November 2014 to October 2017.

\section{Inclusion criteria}

- The study population comprised of low-risk primigravida with singleton, term pregnancy between 37-41 weeks of gestation, with vertex presentation and intact membranes.

\section{Exclusion criteria}

- Patients with ruptured membranes

- Malpresentations

- Multiple pregnancies

- Anomalous pregnancy / Intra-uterine death

- Patients with fetuses having growth restrictions

- Umbilical artery Doppler showing any abnormality or foetal compromise

- Maternal complications like hypertensive disorders,

- Diabetes, Renal and vascular diseases were excluded from the study.

The study population was then divided into two groups:

1. Study group (Cases, $n=51$ ): Term Primigravida's with isolated oligohydramnios

2. $(\mathrm{AFI} \leq 5)$ and a normal color Doppler study.

3. Control group $(n=176)$ : Term Primigravida's with normal AFI (AFI more than 5 but less than equal to 14), after matching with various confounding factors like age, period of gestation etc.

In the present study, 51 cases belonged to the study group whereas, 176 cases belonged to the control group after matching the confounding factors and meeting the inclusion and exclusion criterion for both the groups. AFI in all patients was monitored by the department of Radiodiagnosis, using a four-quadrant technique on a curvilinear probe with frequency 2-5 MHz machine. The data was collected and analysed regarding the mode of delivery, indication of Caesarean Section, birthweight, Apgar Score at 1 minute and 5 minute of birth, meconium aspiration and duration of NICU stay for the neonates delivered.

\section{RESULTS}

After meeting the inclusion and exclusion criterion, it was observed that maximum patients belonged to the age group of 20-29 years in both study and control group. In the study group with Isolated Oligohydramnios,90.2\% (46 patients) women were between 20-29 years of age, with mean maternal age 23.8 years. In the control group $88.6 \%$ (156 patients) were between $20-29$ years of age, with mean maternal age being 24.7 years (Table 1 ).

Table 1: Maternal age distribution.

\begin{tabular}{|l|l|l|}
\hline Maternal age & $\begin{array}{l}\text { Study group } \\
(51)\end{array}$ & $\begin{array}{l}\text { Control group } \\
(176)\end{array}$ \\
\hline$>20$ years & $2(3.9 \%)$ & $9(5.1 \%)$ \\
\hline $20-29$ years & $46(90.2 \%)$ & $156(88.6 \%)$ \\
\hline$>30$ years & $3(5.9 \%)$ & $11(6.3 \%)$ \\
\hline Mean & 23.8 years & 24.7 years \\
\hline
\end{tabular}

Similarly, maximum women were at 38-39 weeks of gestation; $66.7 \%$ (34 patients) in the study group and $67.6 \%$ (119 patients) in the control group (Table 2).

Table 2: Distribution by gestational age.

\begin{tabular}{|l|l|l|}
$\begin{array}{l}\text { Gestational age } \\
\text { (Weeks) }\end{array}$ & $\begin{array}{l}\text { Study group } \\
(51)\end{array}$ & $\begin{array}{l}\text { Control study } \\
(176)\end{array}$ \\
\hline $37-38$ weeks & $15(29.4 \%)$ & $51(29 \%)$ \\
\hline $38-39$ weeks & $34(66.7 \%)$ & $119(67.6 \%)$ \\
\hline$>40$ weeks & $2(3.9 \%)$ & $6(3.4 \%)$ \\
\hline
\end{tabular}

Induction of labour was done in $60.8 \%$ (31) cases in the study group while $39.2 \%$ (20) cases had a spontaneous onset of labour. In the control group, the onset of labour was spontaneous in all patients. The study revealed that $35.3 \%$ (18 cases) underwent a caesarean section in the study group as compared to $13.1 \%$ (23 patients) in the control group (Figure 1). Conversely only 64.7\% (33 patients) had vaginal delivery in the study group when compared to $86.9 \%$ (156 patients) in the control group. This reveals not only higher rate of induction of labour in the study group but also increased operative interference.

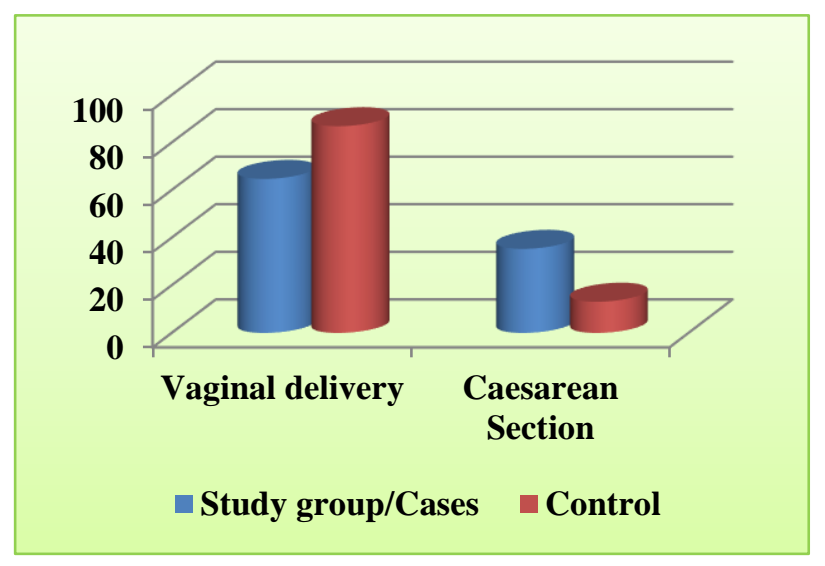

Figure 1: Mode of delivery: vaginal or c-sections. 
Amongst the common causes of caesarean section, it was observed that the most common cause of C.S. in the study group was foetal distress in $55.6 \%$ (10 cases) Vs NonProgress of Labour in $39.1 \%$ (9 cases) in the control group (Figure 2).

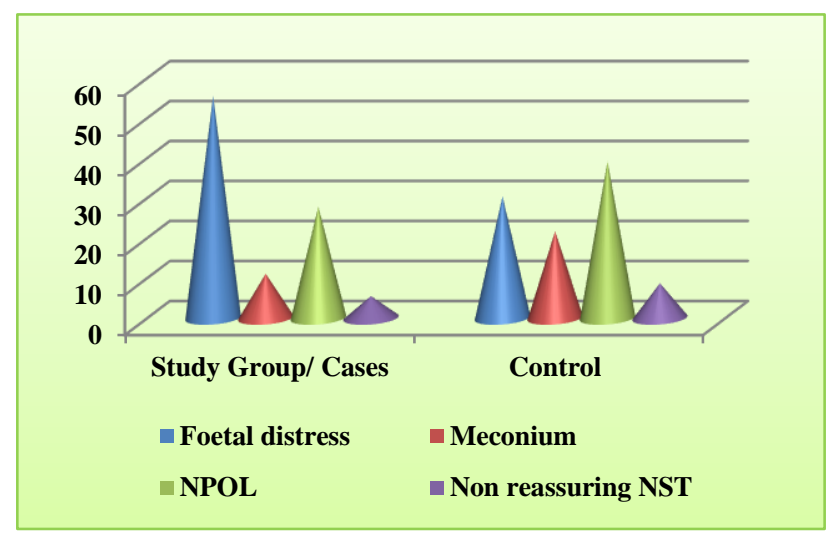

Figure 2: Indications of C-sections.

The other causes of caesarean section in study group were $11.1 \%$ ( 2 patients) for meconium stained liquor, $27.8 \%$ (5 patients) for non-progress of labour and $5.5 \%$ (1 patient) for non-reassuring NST. For the control group, C. Section was performed for Foetal distress $30.4 \%$ (7 patients), meconium stained liquor in $21.8 \%$ (5 patients) and for non- reassuring NST in $8.7 \%$ (2 patients).

Regarding perinatal outcomes, Apgar score $<7$ at 1 min and $5 \mathrm{~min}$ was observed in $15.7 \%$ and $5.7 \%$ respectively in the study group as compared to $6.8 \%$ and $2.3 \%$ in the control group. ${ }^{3,4,8,12}$ However, none of the babies had birth asphyxia. (Table 3 )

Table 3: Perinatal outcomes.

\begin{tabular}{|l|l|l|}
\hline $\begin{array}{l}\text { Mean birth } \\
\text { weight }(\mathrm{kg})\end{array}$ & $2.63 \mathrm{~kg}$ & $2.71 \mathrm{~kg}$ \\
\hline $\begin{array}{l}\text { Apgar score at } \\
\text { 1min }\end{array}$ & $8(15.7 \%)$ & $12(6.8 \%)$ \\
\hline At 5min & $3(5.7 \%)$ & $4(2.3 \%)$ \\
\hline $\begin{array}{l}\text { NICU Admission } \\
>24 \mathrm{hrs}\end{array}$ & $2(3.9 \%)$ & $3(1.7 \%)$ \\
\hline
\end{tabular}

The main reason for NICU admissions for $>24$ hours was meconium aspiration in both the groups. the incidence in study and control groups being only $3.9 \%$ and $1.7 \%$ respectively. ${ }^{2,3}$ the incidence was not statistically significant in both groups (Table 3 ). The mean birth weight of babies in study group $(2.63 \mathrm{~kg})$ was slightly less than the control group $(2.71 \mathrm{~kg})$ which was not statistically significant (Table3).

\section{DISCUSSION}

In present study, it was observed that mean maternal age was 23.8 years in the study group and 24.7 years in the control group, which was comparable to the work by Casey et al. ${ }^{5}$ It was observed that isolated oligohydramnios was associated with increased rate of induction of labour $(60.8 \%)$ and increased operative interference $(35.3 \%)$ in the study group. Our results were comparable to those by Hina et al, where the rate of induction of labour was as high as $63 \%$ in patients with oligohydramnios in their study. ${ }^{6}$ Syed Masuma Rizvi et al, also observed increased rate of induction of labour in patients with oligohydramnios, however the caesarean section rate was quite high $(58 \%)$ in their study. ${ }^{7}$ The possible reason for high $\mathrm{C}$-sections rates could be due to different selection criterion (inclusion of associated risk factors: IUGR,PET ,Breech etc.) taken in their study along with limited methods of fetal surveillance in their set up (as stated by the author). Shrem et al, reported that total caesarean rates were significantly higher in the isolated oligohydramnios group when compared with the normal amniotic fluid group $(13.77 \%$ vs $6.31 \%) .{ }^{8}$ If authors compare the C.S. rates of their study with present study, authors find that C.S. rates in present study group (IO) is almost thrice as high as what was observed in their study ( $35.3 \%$ vs $13.77 \%$ ). The possible reason for the same could be that authors do not perform scalp blood $\mathrm{pH}$ as a method of intrapartum fetal surveillance at our center 1 distress as one of the main indications of C.S. in present study group. Other studies show different rates of caesarean sections in patients with oligohydramnios. Rezaie $\mathrm{K}$ et al, in a US study, reveals only $20.2 \% \mathrm{C}$ section rate. ${ }^{9}$ Whereas in a study performed by Rizvi SM, the C-section was rate was as high as $82 \% .^{7}$ This variation in rates could possibility be due to level of foetal surveillance during labour, indirectly reflecting the quality of obstetric health services.

The most common reason of C-sections in present study group was foetal distress $(55.6 \%)$. This is likely due to cord compression owing to decreased amniotic fluid volume. These results correlate with the study by Krishna Jagatia. $^{10}$

In the present study, as far as perinatal outcome was concerned, authors found that pregnancies complicated by IO were not associated with significant adverse perinatal outcome. The mean birth weight, Apgar score at 5 min and NICU admissions for over 24 hours was not statistically significant in both the groups. This was similar to the observation made by Nankali A. ${ }^{11}$ Results also correlate with a single RCT published by EK et al, where no significant differences were found in mean birth weight and NICU admissions. ${ }^{12}$ This indicates that isolated oligohydramnios is not an indicator of adverse fetal outcome.

\section{CONCLUSION}

As amniotic fluid is an important indicator of placental function, therefore its measurement is of utmost importance to guide the foetal outcome and therefore oligohydramnios is always a reason for potential concern 
to all obstetricians. So much so, it at times becomes the sole reason or indication for caesarean sections. Present study reveals that isolated oligohydramnios is not an indicator of adverse perinatal outcome. Therefore, authors obstetricians need to give a fair trial of labour in such cases (provided no contraindication to vaginal delivery exist). This will not only prevent the avoidable operative maternal morbidity but also help in curbing the rising $\mathrm{C}$-sections rate globally.

Funding: No funding sources

Conflict of interest: None declared

Ethical approval: The study was approved by the Institutional Ethics Committee

\section{REFERENCES}

1. Rabie N, Magann E, Steelman S, Ounpraseuth S. Oligohydramnios in complicated and uncomplicated pregnancy: a systematic review and meta-analysis. Ultrasound Obstet Gynecol. 2017;49(4):442-9.

2. Phelan JP, Smith CV, Broussard P, Small M. Amniotic fluid volume assessment with the fourquadrant technique at $36-42$ weeks' gestation. The J Reprod Med. 1987;32(7):540-2.

3. Cunningham F, Leveno K, Bloom S, Spong CY, Dashe JS, Hoffman BL. Amniotic fluid. Williams Obstet. 24 $4^{\text {th }}$ ed. New York, NY: McGraw Hill. 2014.

4. Nabhan AF, Abdelmoula YA. Amniotic fluid index versus single deepest vertical pocket as a screening test for preventing adverse pregnancy outcome. Cochrane Database of Systematic Reviews. 2008(3).

5. Casey BM, McIntire DD, Bloom SL, Lucas MJ, Santos R, Twickler DM, et al. Pregnancy outcomes after antepartum diagnosis of oligohydramnios at or beyond 34 weeks' gestation. Am J Obstet Gynecol. 2000;182(4):909-12.

6. Ahmad H, Munim S. Isolated oligohydramnios is not an indicator for adverse perinatal outcome. J Pak Med Ass. 2009;59(10):691.

7. Rizvi SM, Farooq S, Farooq M. A study of oligohydramnios at term on maternal and foetal outcome. IJAR. 2017;5(10):652-5.

8. Shrem G, Nagawkar SS, Hallak M, Walfisch A. Isolated oligohydramnios at term as an indication for labor induction: a systematic review and metaanalysis. Fetal Diagnos Therapy. 2016;40(3):161-73.

9. Kahkhaie KR, Keikha F, Keikhaie KR, Abdollahimohammad A, Salehin S. Perinatal outcome after diagnosis of oligohydramnious at term. Iranian Red Cresc Med J. 2014;16(5).

10. Jagatia K, Singh N, Patel S. Maternal and fetal outcome in oligohydramnios: A study of 100 cases. Hypertension. 2013;10(40):0.

11. Nankali A, Hematti M, Talebi A. Fetomaternal outcomes in cases of term oligohydramnios. Women's Heal Gynecol. 2017;3(3).

12. Ek S, Andersson A, Johansson A, Kublicas M. Oligohydramnios in uncomplicated pregnancies beyond 40 completed weeks. Fetal Diagnosis Therapy.2005;20(3):182-5.

Cite this article as: Agarwal S, Gupta S. Neonatal and maternal outcome in term primigravida with isolated oligohydramnios. Int J Reprod Contracept Obstet Gynecol 2019;8:258-61. 